\title{
Hereditary leiomyomatosis and renal cell carcinoma
}

This article was published in the following Dove Press journal: International Journal of Nephrology and Renovascular Disease 20 June 2014

Number of times this article has been viewed

\author{
Laura S Schmidt ${ }^{1,2}$ \\ W Marston Linehan' \\ 'Urologic Oncology Branch, Center \\ for Cancer Research, National Cancer \\ Institute, National Institutes of Health, \\ Bethesda, MD, USA; 'Basic Science \\ Program, Leidos Biomedical Research \\ Inc., Frederick National Laboratory for \\ Cancer Research, Frederick, MD, USA
}

Correspondence: W Marston Linehan Urologic Oncology Branch, Center for Cancer Research, National Cancer Institute - CRC Room IW-5940,

9609 Medical Center Drive,

Bethesda, MD 20892, USA

$\mathrm{Tel}+\mathrm{I} 3014966353$

Fax +l 30I 4020922

Email wml@nih.gov
Abstract: Hereditary leiomyomatosis and renal cell carcinoma (HLRCC) is an autosomal-dominant hereditary syndrome, which is caused by germline mutations in the $F H$ gene that encodes the tricarboxylic acid cycle enzyme fumarate hydratase (FH). HLRCC patients are predisposed to develop cutaneous leiomyomas, multiple, symptomatic uterine fibroids in young women resulting in early hysterectomies, and early onset renal tumors with a type 2 papillary morphology that can progress and metastasize, even when small. Since HLRCC-associated renal tumors can be more aggressive than renal tumors in other hereditary renal cancer syndromes, caution is warranted, and surgical intervention is recommended rather than active surveillance. At-risk members of an HLRCC family who test positive for the familial germline $F H$ mutation should undergo surveillance by annual magnetic resonance imaging from the age of 8 years. Biochemical studies have shown that FH-deficient kidney cancer is characterized by a metabolic shift to aerobic glycolysis. It is hoped that through ongoing clinical trials evaluating targeted molecular therapies, an effective form of treatment for HLRCC-associated kidney cancer will be developed that will offer an improved prognosis for individuals affected with HLRCC-associated kidney cancer.

Keywords: hereditary leiomyomatosis and renal cell carcinoma, HLRCC, FH mutation, type 2 papillary RCC

\section{Introduction}

Renal cell carcinoma (RCC) affects over 271,000 individuals globally, and will result in at least 116,000 deaths this year. ${ }^{1}$ Although $97 \%$ of cases occur in individuals without a family history of renal tumors, it is through the study of inherited renal cancer syndromes that the most progress has been made in deciphering the genetic basis of kidney cancer. Kidney cancer is not a single entity, but a group of distinct diseases, each with a different histology, caused by mutations in a different gene, and with a different clinical course and potential outcome for the patient..$^{2-4}$

Over 2 decades ago, the first cancer gene responsible for an inherited renal cancer syndrome was identified. ${ }^{5}$ Inactivating mutations in the $V H L$ tumor-suppressor gene were identified in the germline of patients with von Hippel-Lindau (VHL) disease, a multisystem disorder that predisposes patients to the development of clear-cell kidney cancer, ${ }^{2,6}$ characterized by the loss of chromosome $3 p .{ }^{7}$ A few years later, a second inherited renal cancer syndrome, hereditary papillary renal carcinoma, was described, in which at-risk individuals developed renal tumors with a papillary type I architecture caused by germline activating mutations in the MET proto-oncogene. ${ }^{8-11}$

Subsequently, Birt-Hogg-Dubé syndrome, originally described as a dermatologic disorder ${ }^{12}$ was reclassified as a renal cancer syndrome when it was discovered that 
patients who inherit a germline mutation in the FLCN tumorsuppressor gene are at risk of developing kidney cancer most frequently, chromophobe and hybrid oncocytic RCC - in addition to benign hair-follicle tumors, pulmonary cysts, and spontaneous pneumothoraces. ${ }^{13-16}$ Finally, germline mutations in genes that encode components of the tricarboxylic acid (TCA) cycle, including the subunits B, C and D of succinate dehydrogenase (SDH) ${ }^{17-19}$ and the $F H$ gene, ${ }^{20}$ predispose individuals to unique inherited renal cancer syndromes and drive metabolic reprogramming of renal tumors. ${ }^{21}$ This review will focus on the inherited renal cancer syndrome caused by germline $\mathrm{FH}$ inactivation, known as hereditary leiomyomatosis and renal cell carcinoma (HLRCC [Online Mendelian Inheritance in Man \{MIM\} 150800]).

\section{Clinical manifestations of HLRCC Skin leiomyomata}

The association of cutaneous leiomyomata with uterine leiomyomata in patients was originally known as Reed's disease. ${ }^{22}$ Subsequently, multiple cutaneous and uterine leiomyoma syndrome (MIM 150800) families in which kidney tumors cosegregated with cutaneous and uterine leiomyomata were identified, and the syndrome was renamed HLRCC. ${ }^{23}$ The most common manifestations of HLRCC are cutaneous leiomyomata, which occur in $76 \%-100 \%$ of patients. ${ }^{24-26}$ They present as multiple firm, flesh-colored nodules ( 10 to $>100$, ranging from 0.4 to $2.5 \mathrm{~mm}$ in size) that develop on the trunk and extremities, sometimes in a segmental pattern, and are often symptomatic, exhibiting pain and paresthesias. Histologically, they are comprised of bundles of smooth-muscle cells with centrally located blunt-ended nuclei (Figure 1). The mean age of onset of these skin lesions is approximately 25 years (range $10-47$ years). ${ }^{24}$

\section{Uterine leiomyomata}

A high percentage of affected women with skin leiomyomata develop uterine leiomyomata (fibroids). ${ }^{24-29}$ Multiple uterine fibroids (up to 20) with a size range of $1.5-10 \mathrm{~cm}$ can occur in an individual. Symptoms may include irregular menses, menorrhagia, and pain, and develop very early
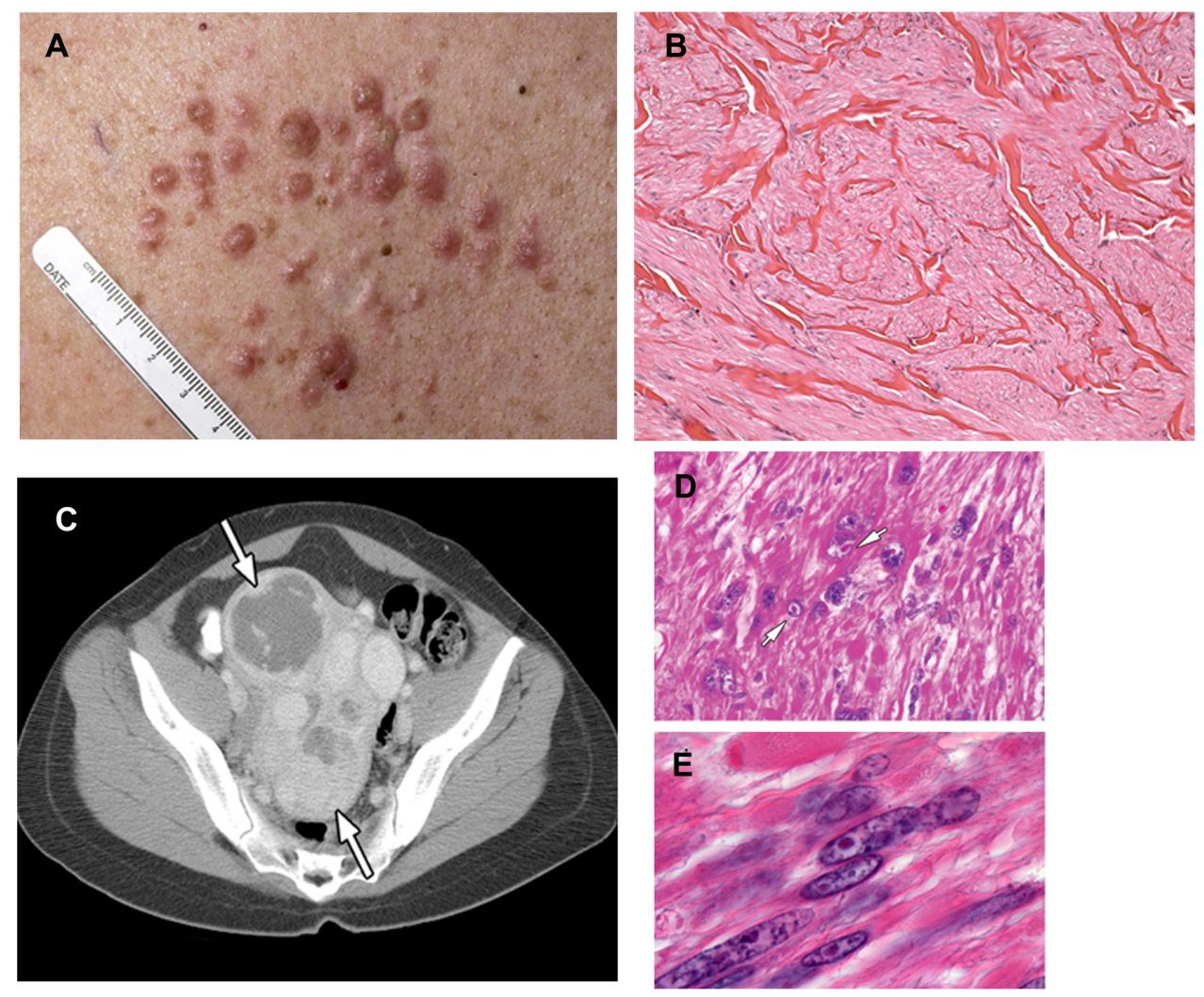

Figure I (A-E) Clinical manifestations of hereditary leiomyomatosis and renal cell carcinoma (HLRCC): leiomyomas.

Notes: (A) Multiple cutaneous leiomyomas on the torso of an HLRCC patient. (B) Histomicrograph of cutaneous leiomyoma, showing interlaced bundles of smooth-muscle fibers with a centrally located long, blunt-edged nucleus. (hematoxylin and eosin, [H\&E] I0X). (C) Computed tomography image showing multiple large uterine leiomyomas (white arrows) that occur in most women with HLRCC, and that can be symptomatic. (D and E) High-power image of a uterine leiomyoma showing large prominent nuclei with an orangiophilic nucleolus (white arrows) surrounded by perinuclear halo; H\&E, 300× and 400×. Images from Grubb et al ${ }^{32}$ (A and C), Rothman et al ${ }^{54}$ (B), and SanzOrtega et $\mathrm{al}^{30}$ (D and $\left.\mathbf{E}\right)$. 
(median 28-32 years). ${ }^{27,30}$ In one study, myomectomies or hysterectomies at or before age 40 years were necessary in $68 \%$ of female HLRCC patients, and half of those women had a hysterectomy or myomectomy at or before 30 years of age. ${ }^{25}$ Histologically, uterine leiomyoma are characterized by cells with large single nuclei or multinucleated cells with orangiophilic prominent nucleoli surrounded by a perinuclear halo (Figure 1). ${ }^{30}$ Although a few rare cases of malignant uterine leiomyosarcoma have been reported among HLRCC patients, ${ }^{23,31}$ currently there is debate about whether these lesions are actually leiomyosarcoma or "atypical histology" commonly seen in HLRCC patients.

\section{Renal tumors, benign cysts, and cystic tumors}

While families characterized by an inherited, autosomal dominant form of a lethal variant of type 2 papillary kidney cancer were described in 1995, the association of this type of kidney cancer with cutaneous and uterine leiomyomata was not made until 2001. ${ }^{23}$ Patients affected with HLRCC are at risk for the development of renal tumors, benign renal cysts, and cystic renal tumors. Renal tumors can occur with an early age of onset (10-44 years), and are characterized by a form of type 2 papillary RCC (Figure 2). ${ }^{23,24,32}$ HLRCCassociated renal tumors may present as solitary lesions; ${ }^{32}$ however, they can also be bilateral and/or multifocal. These kidney tumors can be aggressive and may metastasize even when small. Penetrance for renal tumors in HLRCC is low: $14 \%-18 \%$ of HLRCC patients had been reported to develop kidney cancer in North American and French cohorts; ${ }^{24,33}$ however, in a Dutch study, the frequency was much lower - at 3\%. ${ }^{26}$ Histologically, HLRCC-associated renal tumor cells are characterized by abundant amphophilic cytoplasms and a large nucleus with large inclusion-like eosinophilic or orangiophilic nucleoli surrounded by a clear halo (Figure 2) similar to that seen in uterine leiomyomas from HLRCC patients. ${ }^{34}$ Typically, these tumors display a type 2 papillary architecture, but can have a variety of patterns, including cystic, tubular-papillary, tubular, and solid. ${ }^{34}$ While collecting duct carcinomas have been reported, ${ }^{24,33,35}$ it is not clear whether they are truly collecting duct tumors or simply a variant of HLRCC renal tumors.
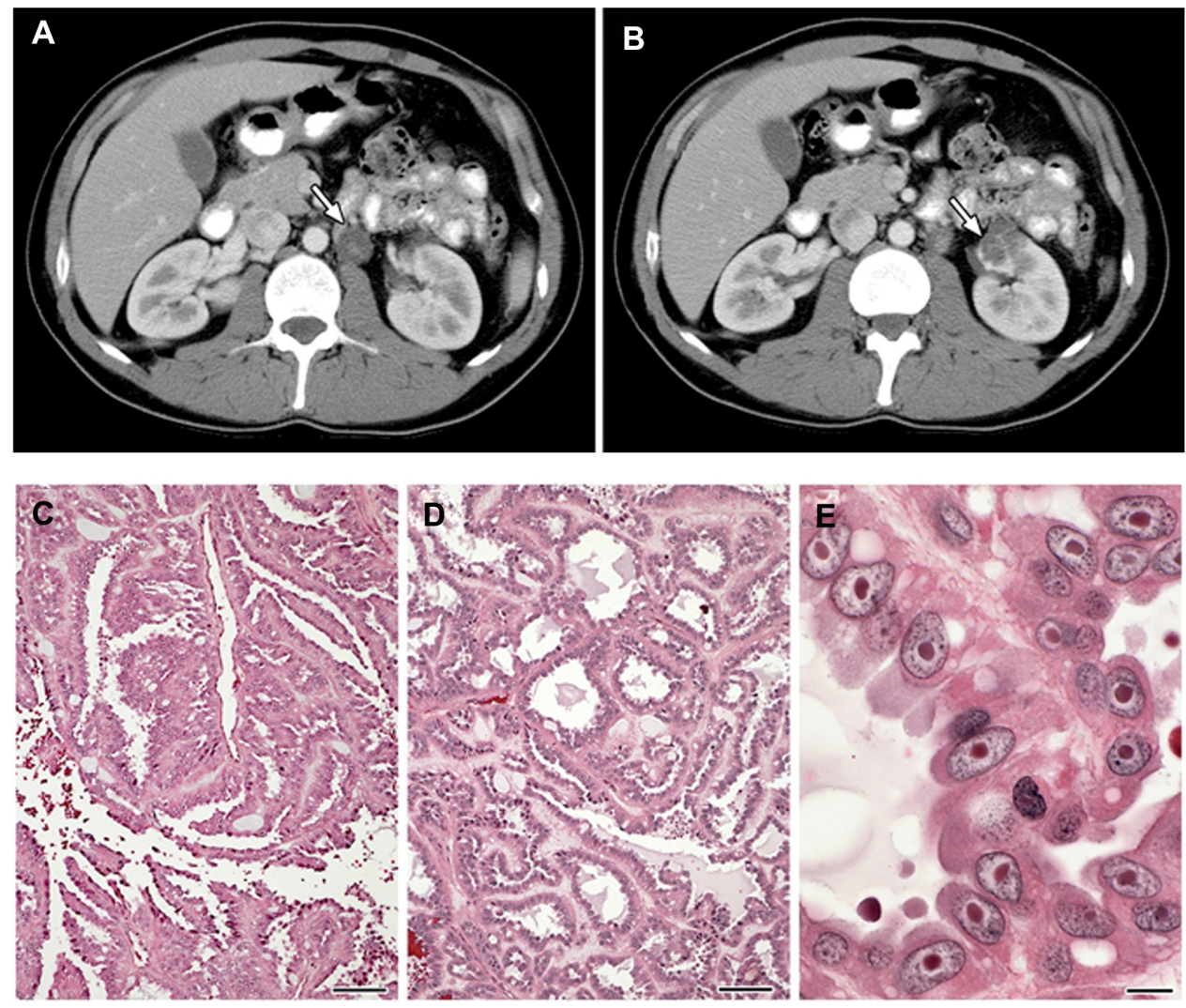

Figure 2 (A-E) Clinical manifestations of hereditary leiomyomatosis and renal cell carcinoma (HLRCC): renal tumors.

Notes: Computed tomography images showing (A) para-aortic nodal disease (white arrow) and (B) left renal tumor (white arrow) in HLRCC patients. RCC in HLRCC patients may present with (C) papillary morphology suggestive of type 2 papillary RCC (IOX), but (D) tubular and cystic patterns may also be seen (I0X). (E) Under high power, the characteristic orangiophilic or eosinophilic nucleoli with perinuclear halo are seen $(40 \times)$. Images from Grubb et al. ${ }^{32}$ Abbreviation: RCC, renal cell carcinoma. 


\section{Other manifestations}

Adrenal cortical adenomas have been reported to occur in $10 \%$ of patients affected with HLRCC..$^{26,36}$ While these tumors are most often small and nonfunctional, a small number of functional tumors (adrenocorticotropic hormoneproducing) have been identified in HLRCC families. ${ }^{36}$

\section{Diagnostic criteria for HLRCC}

Major criteria for a clinical diagnosis of HLRCC in an individual include the presence of multiple skin lesions clinically proven as leiomyomata with at least one histologically confirmed lesion. ${ }^{24}$ Criteria suspicious for HLRCC include: 1) solitary cutaneous leiomyoma and family history of HLRCC, 2) early onset renal tumors that are of type 2 papillary architecture, and 3) in women, multiple early onset uterine leiomyomata that may be symptomatic. The definitive diagnosis of HLRCC is made in an individual by the presence of a germline mutation in the $F H$ gene (Table 1).

\section{Genetic DNA testing and surveillance for HLRCC}

Germline mutations in the $F H$ gene are diagnostic for HLRCC, and genetic testing of the $F H$ gene should be offered to any individual who presents with clinical manifestations of HLRCC or has a family history of HLRCC. Given that highly aggressive renal tumors are part of the syndrome, have been reported in children as young as 11 years of age, ${ }^{37}$ and can metastasize even when small, ${ }^{32}$ it is recommended that genetic testing be offered at the parents' discretion to children as young as $8-10$ years of age. A positive germline mutation result would confirm the diagnosis, whereas a negative germline $\mathrm{FH}$ mutation result (in a patient from a family with a known germline mutation) eliminates the need for lifelong surveillance. A negative germline $F H$ mutation test in an at-risk patient without a known familial mutation does not completely rule out the possibility that the patient is affected with HLRCC. In families with known phenotypic HLRCC evaluated at the Urologic Oncology Branch, National Cancer Institute, the percentage of families who were found to have a positive $F H$ germline mutation test is greater than $95 \%$ (unpublished); however, the detection rate is not currently $100 \%$. The small number of families who phenotypically are characterized as being affected with HLRCC, but test negative for germline $\mathrm{FH}$ mutation, are managed as if they had a positive germline mutation test.

It is recommended that individuals who are affected with or at risk for HLRCC undergo periodic surveillance for kidney tumors. Abdominal magnetic resonance imaging (MRI) with 1-3 mm slices through the kidneys is recommended annually. While renal ultrasound may play a role in assessing complex HLRCC-associated renal mass lesions, this modality is not recommended for either detecting or characterizing HLRCC-associated lesions and is not recommended for screening. MRI screening in $\mathrm{FH}$ mutation-positive children is suggested, starting at the age of 8 years.

\section{Genetic basis of HLRCC}

Germline mutations in the $F H$ gene that encodes the TCA cycle enzyme converting fumarate to malate are responsible for HLRCC. To date, $\sim 120$ unique potentially pathogenic FH mutations have been reported in the Leiden Open Variant Database (http://chromium.liacs.nl/LOVD2/SDH/home. php? select $\mathrm{db}=\mathrm{FH}) .{ }^{38}$ Sanger sequencing of the $\mathrm{FH}$ gene and multiplex ligation-dependent probe amplification have enabled the detection of insertion/deletion, frameshift, nonsense, missense, and splice-site mutations, as well as large gene deletions, increasing the mutation detection rate to nearly $90 \%{ }^{24,25,39}$ An apparent mutational "hot spot" was observed at Arg190 (Arg190His, Arg190Leu, Arg190Cys) in 18 of 56 unrelated families in a North American cohor ${ }^{24,25}$ and in 14 of 45 families in a British cohort. ${ }^{39}$ Founder mutations have been reported among three Dutch HLRCC families, ${ }^{26}$ four families of Jewish Iranian origin, ${ }^{40}$ and a German and an English family. ${ }^{41,42}$ Reduced or loss of fumarate hydratase (FH) enzyme activity was detected in lymphoblastoid and fibroblast cells from HLRCC patients, ${ }^{20,25,35,43}$ and may serve as a useful diagnostic tool for identifying $\mathrm{FH}$ mutation carriers in cases where sequencing and multiplex ligation-dependent probe amplification have not identified any $F H$ variant or gene deletion. Since FH is a tetrameric protein, the fact that lymphoblastoid cells from patients with germline $\mathrm{FH}$ missense mutations expressed very low FH activity may be due to a dominant negative effect of the FH missense mutant protein preventing the formation of fully functional FH tetramers. ${ }^{35}$

\section{Molecular consequences of $\mathrm{FH}$ inactivation in HLRCC}

Kidney tumors, uterine fibroids, and cutaneous leiomyomas from HLRCC patients with $F H$ germline mutations acquire a "second hit" by somatic loss or mutation of the wild-type $\mathrm{FH}$ allele underscoring a tumor-suppressor role for $F H^{20,23,35}$ Inactivation of both $\mathrm{FH}$ alleles results in loss of FH activity in the target tissues (kidney tumors, cutaneous and uterine leiomyomas), thereby inhibiting the conversion of fumarate to malate and resulting in fumarate accumulation. There are a number of proposed mechanisms by which elevated fumarate may function as an oncoprotein in FHdeficient kidney cancer. 
Loss of FH activity results in accumulation of fumarate, which may be transported out of the mitochondria into the cytoplasm. In the cytoplasm, elevated levels of fumarate can competitively inhibit the function of hypoxia-inducible factor (HIF) prolyl hydroxylase, resulting in HIF accumulation. ${ }^{4}$ With increased HIF-1 $\alpha$ levels, HIF target genes, such as $V E G F$ and $G L U T 1$, are transcriptionally activated, providing increased vasculature and glucose transport for these glucosedependent FH-deficient tumors (Figure 3). ${ }^{44,45}$

In addition, fumarate is an electrophile, and reacts spontaneously with the sulfhydryl moiety of cysteines, a reaction termed succination, ${ }^{46}$ which is known to modify the activity of a number of proteins and can be detected by an immunohistochemical assay. ${ }^{47}$ One of these proteins is KEAP1, which is the substrate recognition subunit of a cullin 3 (CUL3)-based E3 ubiquitin-ligase complex that targets nuclear factor erythroid 2-related factor 2 (Nrf2) for degradation in the proteasome. Nrf2 drives an adaptive response of cells to electrophilic and oxidative stress by transcriptionally upregulating target genes containing antioxidant-response elements in their promoters. In the absence of electrophiles, KEAP1 through CUL3 binds to Nrf2 and targets it for ubiquitin-mediated degradation. ${ }^{48}$ Electrophiles such as fumarate can succinate critical KEAP1 cysteines, resulting in a conformational change that abrogates KEAP1-Nrf2 binding, leading to stabilization and accumulation of Nrf2, and the activation of the Nrf2 antioxidant pathway (Figure 3). ${ }^{49,50}$ In this context, fumarate acts as an oncometabolite. ${ }^{51}$ If dysregulation of the KEAP1-Nrf2-CUL3 pathway represents an additional mechanism facilitating tumor formation in HLRCC, this may represent an opportunity for developing targeted therapies for HLRCC-associated renal cancer.

\section{Clinical management of HLRCC and treatment of manifestations}

Clinical management of HLRCC patients requires a multidisciplinary approach involving dermatologists, gynecologists, and urologic oncologists. Genetic counseling is extremely important for patients with a family history of HLRCC to identify asymptomatic at-risk family members and initiate surveillance at an early age.

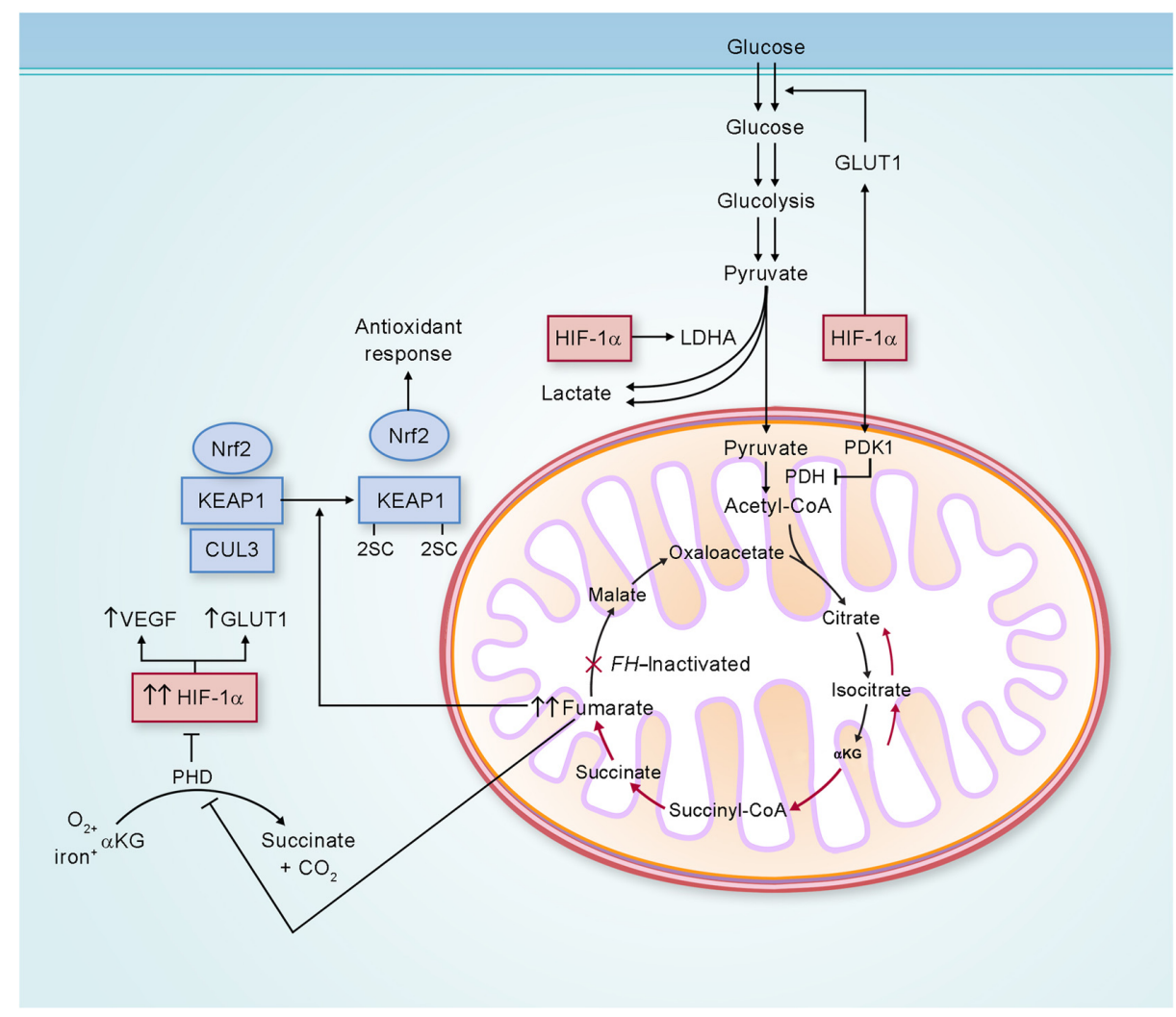

Figure 3 Potential biochemical pathways deregulated as a consequence of $F H$ inactivation.

Notes: FH-deficient kidney cancer has impaired oxidative phosphorylation, and undergoes a metabolic shift to aerobic glycolysis to generate adenosine triphosphate for cellular energy demands. Fumarate, which accumulates in FH-deficient cells, can competitively inhibit prolyl hydroxylase (PHD), resulting in HIF-I $\alpha$ stabilization and increased expression of the HIF-I $\alpha$ target genes VEGF and GLUTI. Elevated fumarate also succinates KEAPI, altering its conformation and inhibiting its ability to degrade nuclear factor erythroid 2-related factor 2 (Nrf2). Nrf2 transcriptional activity is upregulated, leading to activation of the antioxidant-response pathway and protection against oxidative stress. Adapted from Linehan and Rouault. ${ }^{21}$ Abbreviations: LDHA, lactate dehydrogenase A; CoA, coenzyme A; $\alpha$ KG, $\alpha$-ketoglutarate; FH, fumarate hydratase; GLUTI, glucose transporter I; KEAPI, kelch-like ECH-associated protein I; CUL3, cullin 3; HIF-I $\alpha$, hypoxia-inducible factor I alpha; VEGF, vascular endothelial growth factor; PDH, pyruvate dehydrogenase; PDKI, pyruvate dehydrogenase kinase I. 


\section{Cutaneous leiomyomas}

An important goal of treatment for patients with cutaneous leiomyomas is to alleviate pain in these benign lesions. Medications, such as nifedipine, gabapentin, doxasozin, phenoxybenzamine, hyoscine, hydrobromide, and nitroglycerin have been used. ${ }^{52}$ Single leiomyomas may be removed surgically. Multiple cutaneous lesions may be treated with electrocoagulation, cryotherapy, or $\mathrm{CO}_{2}$ laser ablation in combination with pain-relieving medications, including analgesics, antidepressants, and opioid (oxycodone) drugs. ${ }^{52,53}$

\section{Uterine leiomyomas}

Early onset ( $<40$ years) symptomatic uterine leiomyomas (fibroids) are a highly penetrant manifestation in women with HLRCC, and are associated with an increased frequency of surgical treatment at a young age compared to $F H$ mutationnegative women. ${ }^{27}$ An annual gynecologic consultation is suggested to assess the severity of uterine fibroids. Hysterectomy may be recommended due to the large size and number of fibroids; however, myomectomy is commonly preferred to conserve uterine function.

\section{Renal cancer}

Kidney tumors that develop in the setting of HLRCC can be aggressive and may metastasize, even when small. It is recommended that individuals with a germline $\mathrm{FH}$ mutation be screened for renal tumors by annual abdominal imaging starting at 8 years of age (see the "Genetic DNA testing and surveillance for HLRCC" section). The modalities of choice are MRI and/or computerized tomography, depending on the clinicians' preference and the need to decrease lifelong radiation exposure. ${ }^{32}$ Renal ultrasound is not recommended for routine screening; however, this modality may be utilized by the clinician to help further characterize a complex renal cystic lesion detected on computerized tomography scan or MRI.

Table I Diagnostic criteria for hereditary leiomyomatosis and renal cell carcinoma (HLRCC)

Major criteria (high likelihood of HLRCC)

- Multiple cutaneous leiomyomata with at least one biopsy proven/ histologically confirmed

Minor criteria (suspicious for HLRCC)

- Solitary cutaneous leiomyoma and family history of HLRCC

- Early onset renal tumors of type 2 papillary histology

- Multiple early onset ( $<40$ years) symptomatic uterine fibroids

Definitive diagnosis

- Positive germline $\mathrm{FH}$-mutation test
Surgical resection using nephron-sparing techniques is a preferred method of treatment, when possible, for HLRCCassociated kidney tumors. Unlike the management of kidney tumors that develop in other inherited kidney cancer syndromes, such as VHL, hereditary papillary renal carcinoma, or Birt-Hogg-Dubé syndrome, active surveillance until the largest tumor reaches $3 \mathrm{~cm}$ in size is not recommended for HLRCC-associated kidney tumors, as they have a propensity to metastasize even at a size less than $1 \mathrm{~cm} .{ }^{32}$ Cryoablation and radiofrequency ablation are not recommended for the management of HLRCC-associated renal tumors.

\section{Therapeutic approach for patients with advanced HLRCC-associated renal tumors}

Metastatic HLRCC-associated kidney cancer is refractory to conventional targeted therapeutic approaches, and is a disease that can be rapidly fatal. A therapeutic approach has been developed utilizing bevacizumab, an agent that targets vascular endothelial growth factor A (VEGFA), combined with erlotinib, which targets epidermal growth factor receptor (EGFR) kinase activity. A Phase II clinical trial (NCI 10-C-0114) is currently being conducted at the National Cancer Institute, evaluating the effect of bevacizumab plus erlotinib in patients with advanced HLRCC-associated kidney cancer (NCT01130519).

\section{Conclusion}

HLRCC is an autosomal-dominant inherited renal cancer syndrome in which affected individuals are at risk for the development of cutaneous leiomyomas, symptomatic early onset uterine leiomyomas, and an aggressive form of type 2 papillary kidney cancer. The clinical diagnosis for HLRCC is confirmed by the presence of multiple skin lesions with at least one histologically proven leiomyoma. This disorder is characterized by germline mutations in the gene for the TCA cycle enzyme - FH. Germline $F H$ mutation testing is important for all at-risk family members, since the early onset renal tumors that develop in HLRCC patients can progress and metastasize even when small. At-risk members of HLRCC families who test positive for the family's germline $\mathrm{FH}$ mutation should undergo annual MRI surveillance beginning at the age of 8 years. Early detection and immediate surgical intervention for HLRCC-associated kidney tumors, rather than active surveillance, are critical to preventing the metastatic spread of this malignancy. Biochemical studies have shown that FH-deficient kidney cancer is characterized by a metabolic shift to aerobic glycolysis. Hopefully, clinical trials underway evaluating targeted therapeutic approaches for 
patients affected with advanced forms of HLRCC-associated kidney cancer will provide the foundation for the development of effective forms of therapy for this disease.

\section{Acknowledgments}

This research was supported by the Intramural Research Program of the National Institutes of Health, National Cancer Institute, Center for Cancer Research. This project has been funded in part with federal funds from the Frederick National Laboratory for Cancer Research, National Institutes of Health, under contract HHSN261200800001E. The content of this publication does not necessarily reflect the views or policies of the Department of Health and Human Services, nor does mention of trade names, commercial products, or organizations imply endorsement by the US government.

\section{Disclosure}

The authors report no conflicts of interest in this work.

\section{References}

1. Ferlay J, Shin HR, Bray F, Forman D, Mathers C, Parkin DM. Estimates of worldwide burden of cancer in 2008: GLOBOCAN 2008. Int J Cancer. 2010;127:2893-2917.

2. Linehan WM, Walther MM, Zbar B. The genetic basis of cancer of the kidney. J Urol. 2003;170:2163-2172.

3. Linehan WM. Genetic basis of kidney cancer: role of genomics for the development of disease-based therapeutics. Genome Res. 2012;22:2089-2100.

4. Linehan WM, Srinivasan R, Schmidt LS. The genetic basis of kidney cancer: a metabolic disease. Nat Rev Urol. 2010;7:277-285.

5. Latif F, Tory K, Gnarra JR, et al. Identification of the von Hippel-Lindau disease tumor suppressor gene. Science. 1993;260:1317-1320.

6. Lonser RR, Glenn GM, Walther MM, et al. von Hippel-Lindau disease. Lancet. 2003;361:2059-2067.

7. Cancer Genome Atlas Research Network. Comprehensive molecular characterization of clear cell renal cell carcinoma. Nature. 2013;499:43-49.

8. Zbar B, Glenn GM, Lubensky IA, et al. Hereditary papillary renal cell carcinoma: clinical studies in 10 families. $J$ Urol. 1995;153: 907-912.

9. Schmidt LS, Duh FM, Chen F, et al. Germline and somatic mutations in the tyrosine kinase domain of the MET proto-oncogene in papillary renal carcinomas. Nat Genet. 1997;16:68-73.

10. Jeffers M, Schmidt LS, Nakaigawa N, et al. Activating mutations for the met tyrosine kinase receptor in human cancer. Proc Natl Acad Sci US A. 1997;94:11445-11450.

11. Miller M, Ginalski K, Lesyng B, Nakaigawa N, Schmidt L, Zbar B. Structural basis of oncogenic activation caused by point mutations in the kinase domain of the MET proto-oncogene: modeling studies. Proteins. 2001;44:32-43.

12. Birt AR, Hogg GR, Dubé WJ. Hereditary multiple fibrofolliculomas with trichodiscomas and acrochordons. Arch Dermatol. 1977;113: 1674-1677.

13. Toro JR, Glenn G, Duray P, et al. Birt-Hogg-Dubé syndrome: a novel marker of kidney neoplasia. Arch Dermatol. 1999;135:1195-1202.

14. Nickerson ML, Warren MB, Toro JR, et al. Mutations in a novel gene lead to kidney tumors, lung wall defects, and benign tumors of the hair follicle in patients with the Birt-Hogg-Dubé syndrome. Cancer Cell. 2002;2:157-164
15. Zbar B, Alvord WG, Glenn GM, et al. Risk of renal and colonic neoplasms and spontaneous pneumothorax in the Birt-HoggDubé syndrome. Cancer Epidemiol Biomarkers Prev. 2002;11: 393-400.

16. Pavlovich CP, Walther MM, Eyler RA, et al. Renal tumors in the Birt-Hogg-Dubé syndrome. Am J Surg Pathol. 2002;26:1542-1552.

17. Vanharanta S, Buchta M, McWhinney SR, et al. Early-onset renal cell carcinoma as a novel extraparaganglial component of SDHB-associated heritable paraganglioma. Am J Hum Genet. 2004;74:153-159.

18. Malinoc A, Sullivan M, Wiech T, et al. Biallelic inactivation of the SDHC gene in renal carcinoma associated with paraganglioma syndrome type 3. Endocr Relat Cancer. 2012;19:283-290.

19. Ricketts CJ, Shuch B, Vocke CD, et al. Succinate dehydrogenase kidney cancer: an aggressive example of the Warburg effect in cancer. $J$ Urol. 2012;188:2063-2071.

20. Tomlinson IP, Alam NA, Rowan AJ, et al. Germline mutations in FH predispose to dominantly inherited uterine fibroids, skin leiomyomata and papillary renal cell cancer. Nat Genet. 2002;30:406-410.

21. Linehan WM, Rouault TA. Molecular pathways: fumarate hydratasedeficient kidney cancer - targeting the Warburg effect in cancer. Clin Cancer Res. 2013;19:3345-3352.

22. Reed WB, Walker R, Horowitz R. Cutaneous leiomyomata with uterine leiomyomata. Acta Derm Venereol. 1973;53:409-416.

23. Launonen V, Vierimaa O, Kiuru M, et al. Inherited susceptibility to uterine leiomyomas and renal cell cancer. Proc Natl Acad Sci U S A. 2001;98:3387-3392.

24. Toro JR, Nickerson ML, Wei MH, et al. Mutations in the fumarate hydratase gene cause hereditary leiomyomatosis and renal cell cancer in families in North America. Am J Hum Genet. 2003;73:95-106.

25. Wei MH, Toure O, Glenn GM, et al. Novel mutations in FH and expansion of the spectrum of phenotypes expressed in families with hereditary leiomyomatosis and renal cell cancer. J Med Genet. 2006;43:18-27.

26. Smit DL, Mensenkamp AR, Badeloe S, et al. Hereditary leiomyomatosis and renal cell cancer in families referred for fumarate hydratase germline mutation analysis. Clin Genet. 2011;79:49-59.

27. Stewart L, Glenn GM, Stratton P, et al. Association of germline mutations in the fumarate hydratase gene and uterine fibroids in women with hereditary leiomyomatosis and renal cell cancer. Arch Dermatol. 2008;144:1584-1592.

28. Alam NA, Barclay E, Rowan AJ, et al. Clinical features of multiple cutaneous and uterine leiomyomatosis: an underdiagnosed tumor syndrome. Arch Dermatol. 2005;141:199-206.

29. Martinez-Mir A, Glaser B, Chuang GS, et al. Germline fumarate hydratase mutations in families with multiple cutaneous and uterine leiomyomata. J Invest Dermatol. 2003;121:741-744.

30. Sanz-Ortega J, Vocke C, Stratton P, Linehan WM, Merino MJ. Morphologic and molecular characteristics of uterine leiomyomas in hereditary leiomyomatosis and renal cancer (HLRCC) syndrome. Am J Surg Pathol. 2013;37:74-80.

31. Lehtonen R, Kiuru M, Vanharanta S, et al. Biallelic inactivation of fumarate hydratase $(\mathrm{FH})$ occurs in nonsyndromic uterine leiomyomas but is rare in other tumors. Am J Pathol. 2004;164:17-22.

32. Grubb RL 3rd, Franks ME, Toro J, et al. Hereditary leiomyomatosis and renal cell cancer: a syndrome associated with an aggressive form of inherited renal cancer. J Urol. 2007;177:2074-2080.

33. Gardie B, Remenieras A, Kattygnarath D, et al. Novel FH mutations in families with hereditary leiomyomatosis and renal cell cancer (HLRCC) and patients with isolated type 2 papillary renal cell carcinoma. $J$ Med Genet. 2011;48:226-234.

34. Merino MJ, Torres-Cabala C, Pinto PA, Linehan WM. The morphologic spectrum of kidney tumors in hereditary leiomyomatosis and renal cell carcinoma (HLRCC) syndrome. Am J Surg Pathol. 2007;31:1578-1585.

35. Alam NA, Rowan AJ, Wortham NC, et al. Genetic and functional analyses of FH mutations in multiple cutaneous and uterine leiomyomatosis, hereditary leiomyomatosis and renal cancer, and fumarate hydratase deficiency. Hum Mol Genet. 2003;12:1241-1252. 
36. Shuch B, Ricketts CJ, Vocke CD, et al. Adrenal nodular hyperplasia in hereditary leiomyomatosis and renal cell cancer. J Urol. 2013;189: $430-435$.

37. Alrashdi I, Levine S, Paterson J, et al. Hereditary leiomyomatosis and renal cell carcinoma: very early diagnosis of renal cancer in a paediatric patient. Fam Cancer. 2010;9:239-243.

38. Bayley JP, Launonen V, Tomlinson IP. The FH mutation database: an online database of fumarate hydratase mutations involved in the MCUL (HLRCC) tumor syndrome and congenital fumarase deficiency. BMC Med Genet. 2008;9:20.

39. Alam NA, Olpin S, Leigh IM. Fumarate hydratase mutations and predisposition to cutaneous leiomyomas, uterine leiomyomas and renal cancer. Br J Dermatol. 2005;153:11-17.

40. Chuang GS, Martinez-Mir A, Geyer A, et al. Germline fumarate hydratase mutations and evidence for a founder mutation underlying multiple cutaneous and uterine leiomyomata. J Am Acad Dermatol. 2005;52:410-416.

41. Chan I, Wong T, Martinez-Mir A, Christiano AM, McGrath JA. Familial multiple cutaneous and uterine leiomyomas associated with papillary renal cell cancer. Clin Exp Dermatol. 2005;30:75-78.

42. Heinritz W, Paasch U, Sticherling M, et al. Evidence for a founder effect of the germline fumarate hydratase gene mutation R58P causing hereditary leiomyomatosis and renal cell cancer (HLRCC). Ann Hum Genet. 2008;72:35-40.

43. Pithukpakorn M, Wei MH, Toure O, et al. Fumarate hydratase enzyme activity in lymphoblastoid cells and fibroblasts of individuals in families with hereditary leiomyomatosis and renal cell cancer. J Med Genet. 2006;43:755-762.

44. Isaacs JS, Jung YJ, Mole DR, et al. HIF overexpression correlates with biallelic loss of fumarate hydratase in renal cancer: novel role of fumarate in regulation of HIF stability. Cancer Cell. 2005;8:143-153.

45. Pollard PJ, Briere JJ, Alam NA, B et al. Accumulation of Krebs cycle intermediates and over-expression of HIF $1 \alpha$ in tumours which result from germline FH and SDH mutations. Hum Mol Genet. 2005;14: 2231-2239.
46. Alderson NL, Wang Y, Blatnik M, et al. S-(2-succinyl)cysteine: a novel chemical modification of tissue proteins by a Krebs cycle intermediate. Arch Biochem Biophys. 2006;450:1-8.

47. Bardella C, El-Bahrawy M, Frizzell N, et al. Aberrant succination of proteins in fumarate hydratase-deficient mice and HLRCC patients is a robust biomarker of mutation status. J Pathol. 2011;225: 4-11.

48. Kansanen E, Kuosmanen SM, Leinonen H, Levonen AL. The Keap1Nrf2 pathway: mechanisms of activation and dysregulation in cancer. Redox Biol. 2013;1:45-49.

49. Adam J, Hatipoglu E, O'Flaherty L, et al. Renal cyst formation in Fh1-deficient mice is independent of the Hif/Phd pathway: roles for fumarate in KEAP1 succination and Nrf2 signaling. Cancer Cell. 2011;20:524-537.

50. Ooi A, Wong JC, Petillo D, et al. An antioxidant response phenotype shared between hereditary and sporadic type 2 papillary renal cell carcinoma. Cancer Cell. 2011;20:511-523.

51. Yang M, Soga T, Pollard PJ, Adam J. The emerging role of fumarate as an oncometabolite. Front Oncol. 2012;2:85.

52. Choudhary S, McLeod M, Torchia D, Romanelli P. Multiple cutaneous and uterine leiomyomatosis syndrome: a review. J Clin Aesthet Dermatol. 2013;6:16-21.

53. Ritzmann S, Hanneken S, Neumann NJ, Ruzicka T, Kruse R. Type 2 segmental manifestation of cutaneous leiomyomatosis in four unrelated women with additional uterine leiomyomas (Reed's syndrome). Dermatology. 2006;212:84-87.

54. Rothman A, Glenn GM, Choyke L, Srinivasan R, Linehan WM, Cowen EW. Multiple painful cutaneous nodules and renal mass. $J$ Am Acad Dermatol. 2006;55:683-686.

\section{Publish your work in this journal}

The International Journal of Nephrology and Renovascular Disease is an international, peer-reviewed open-access journal focusing on the pathophysiology of the kidney and vascular supply. Epidemiology, screening, diagnosis, and treatment interventions are covered as well as basic science, biochemical and immunological studies. The journal welcomes original research, clinical studies, reviews \& evaluations, expert opinion and commentary, case reports and extended reports. The manuscript management system is completely online and includes a very quick and fair peerreview system, which is all easy to use. Visit http://www.dovepress.com/ testimonials.php to read real quotes from published authors. 